Jpn J Human Genet 42, 539-541, 1997

Short Communication

\title{
AGENESIS OF CORPUS CALLOSUM IN THREE SIBS
}

\author{
Kenji NaritomI, ${ }^{*}$ Yasutsugu ChInen, and Yoshihide Asato \\ Department of Pediatrics, University of the Ryukyus School of \\ Medicine, 207 Uehara, Nishihara, Okinawa 903-01, Japan
}

Summary We report on a rare familial cases with complete agenesis of the corpus callosum found in three sibs, in which autosomal recessive mode of inheritance was suggested.

Key Words agenesis of the corpus callosum, autosomal recessive inheritance

\section{Introduction}

Agenesis of the corpus callosum has many genetic causes, and sporadic occurrence is not uncommon (Dobyns, 1996). However, familial cases without known malformation syndromes are rare. The mode of inheritance are autosomal recessive (MIM\# 217990) (Naiman and Fraser, 1955; Shapira and Cohen, 1973; Pineda et al., 1984; Young et al., 1985), autosomal dominant (Lynn et al., 1980; Inbar et al., 1997), and X-linked recessive (MIM\#*314100) (Menkes et al., 1964; Kaplan, 1983; Wilson et al., 1983; Kang et al., 1992).

We report on three ribs with complete agenesis of the corpus callosum.

\section{Case Reports}

Three sibs were referred to us for genetic evaluation of severe developmental retardation and agenesis of the corpus callosum. The propositi were a 3-year-old boy (case 1) and his one-year-old dizygotic twin sister and brother (cases 2 and 3 ) (Fig. 1). The father was 37 , and the mother was 34 years of age. The pregnancies and deliveries of these three cases were unremarkable. The mother had two normal female children between the former husband, and three consecutive spontaneous abortions among the propositi all at two months of gestation. The paternal grand parents and maternal grandmother were born in the narrow district of same town. Psychomotor development in case 1 was severely retarded; initial gait at 21 months, and no meaningful words at 3 years of age. Complete agenesis of the corpus callosum was verified on an MRI scanning in all of them (Fig. 2). Corpus callosum was normal in the parents. Other common physical findings were general-

Received June 12, 1997; Revised version accepted July 14, 1997.

*To whom correspondence should be addressed. 

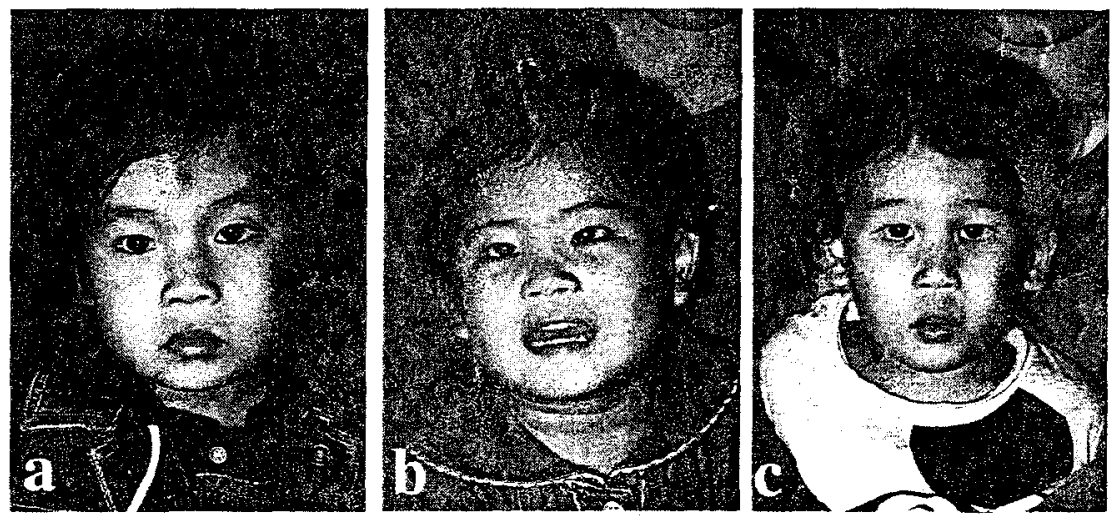

Fig. 1. Facial appearance (a) case 1, (b) case 2, and (c) case 3.

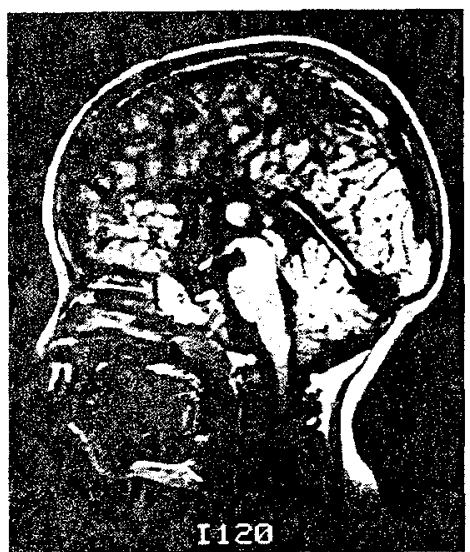

Fig. 2. Complete agenesis of the corpus callosum (case 1).

ized hypotonia, frontal bossing, dolichocephaly, high nasal bridge, prominent ears, and strabismus. In addition, deep-set eyes, high-arched palate and carp-like mouth were seen in cases 2 and 3. Ophthalmological examinations were normal in cases 1 and 2 as well as $X$-ray findings of the vertebrae. The karyotype was normal in case 2. Initial gait was delayed to 21 months of age in case 1 . At the last visit of two years later, psychomotor development of twins were almost similar to case 1.

\section{Discussion}

Agenesis of the corpus callosum has many genetic causes, and sporadic occurrence is not uncommon (Dobyns, 1996). Indeed, agenesis of the corpus callosum is a part of clinical findings in more than 150 malformation syndromes (Naritomi, 1997). All of them were denied in present cases. However, familial cases 
without known malformation syndromes are rare. The mode of inheritance are autosomal recessive (MIM\# 217990) (Naiman and Fraser, 1955; Shapira and Cohen, 1973; Pineda et al., 1984; Young et al., 1985), autosomal dominant (Lynn et al., 1980; Inbar et al., 1997), and X-linked recessive (MIM\#*314100) (Menkes et al., 1964; Kaplan, 1983; Wilson et al., 1983; Kang et al., 1992). Psychomotor retardation is usually severe except for milder retardation in autosomal dominant cases. In present cases, although the parents denied consanguinity, autosomal recessive mode of inheritance was highly suggested by the pedigree. All of the propositi had complete agenesis of the corpus callosum and severe psychomotor retardation (no meaningful words). In addition, they had some common dysmorphic stigmata (frontal bossing, dolichocephaly, deep-set eyes, strabismus, high nasal bridge, prominent ears, high-arched palate, carp-like mouth, Dubois' sign, and mildly broad halluces). Their phenotype is similar to the cases reported by Young et al. (1985).

\section{REFERENCES}

Dobyns WB (1996): Absence makes the search grow longer. Am J Hum Genet 58: 7-16

Inbar D, Halpern GJ, Weitz R, Sadeh M, Shohat M (1997): Agenesis of the corpus callosum in a mother and son. Am J Med Genet 69: 152-154

Kang W-M, Huang C-C, Lin S-J (1992): X-linked recessive inheritance of dysgenesis of corpus callosum in a Chinese family. Am J Med Genet 44: 619-623

Kaplan P (1983): X-linked recessive inheritance of agenesis of the corpus callosum. J Med Genet 20: $122-124$

Lynn RB, Buchanan DC, Fenichel GM, Freemon FR (1980): Agenensis of the corpus callosum. Arch Neurol 37: 444-445

Menkes JH, Phillippart M, Clark DB (1964): Hereditary partial agenesis of corpus callosum. Arch Neurol 11: $198-208$

Naiman J, Fraser FC (1955): Agenesis of the corpus callosum: a report of two cases in siblings. Arch Neurol Psychiatry 74: 182-185

Naritomi K (1997): University of the Ryukyus database for malformation syndromes, ver. 4.0, Department of Pediatrics, University of the Ryukyus, Nishihara, Okinawa

Pineda M, Gonzalez A, Fàbregues I, Fernândez-Alvarez E (1984): Familial agenesis of the corpus callosum with hypothermia and apneic spells. Neuropediatrics 15: 63-67

Shapira Y, Cohen T (1973): Agenesis of the corpus callosum in two sisters. J Med Genet 10: 266269

Wilson WG, Kennauch JM, Kugler JP, Reynolds JF (1983): Agenesis of the corpus callosum in two brothers. J Med Genet 20: 416-418

Young ID, Trounce JQ, Levene MI, Fitzsimmons JS, Moore JR (1985): Agenesis of the corpus callosum and macrocephaly in siblings. Clin Genet 28: 225-230 